\title{
A VARIAÇÃO DO RÓTICO EM CIDADES \\ TOCANTINENSES: EM BUSCA DE UMA NORMA FONÉTICA
}

Variations in rhotic pronunciation in towns of the state of tocantins, brazil: looking for a phonetic norm

Variación del "rótico" en ciudades del tocantins: en busca de una norma fonética

\section{Bruna Lorraynne Dias Menezes ${ }^{*}$, Greize Alves da Silva ${ }^{2}$}

${ }^{1}$ Graduada em Letras, Universidade Federal do Tocantins, campus de Porto Nacional, Brasil.

${ }^{1}$ Professora adjunta do curso de Letras, Universidade Federal do Tocantins, campus de Porto Nacional, Brasil.

*Correspondência: UFT - Universidade Federal do Tocantins, Colegiado de Letras, R. 03, s/n, Jardim dos Ipês, Porto Nacional, Tocantins, Brasil.CEP:77.500-000.e-mail letrasporto@uft.edu.br.

\section{RESUMO}

O Tocantins possui 28 anos de emancipação política e se caracteriza por sua diversidade linguística, fruto dos intensos fluxos migratórios de pessoas procedentes, principalmente, do Maranhão, do Piauí, da Bahia e do Pará. Dentre as cidades que receberam grandes levas migratórias destacamos Porto Nacional, Pedro Afonso e Natividade, fundadas ainda no antigo norte goiano e que se constituem como importantes polos históricos, formados tanto por pessoas autóctones quanto por migrantes procedentes de diferentes regiões. Nesse interim, e partindo do pressuposto de que as citadas cidades podem apresentar importantes aspectos variacionistas do português falado no Tocantins, o presente trabalho possuiu a finalidade de identificar e analisar os róticos, grafematicamente representado por /R/, em posição de coda silábica, nas três mencionadas cidades. As pesquisas de campo foram realizadas junto a 24 informantes topodinâmicos e topoestáticos, distribuídos pelas variáveis sexo e idade. Analisamos um extrato de questionário contendo 25 questões coletadas pelo projeto "Atlas Linguístico Topodinâmico Topoestático do Estado do Tocantins (ALiTTETO)".

Palavras-chave: Tocantins, Rótico, Variação Linguística.

\section{ABSTRACT}

The political emancipation of the state of Tocantins, Brazil, occurred 28 years ago, The state is characterized by linguistic varieties due to the intense migratory flow of people hailing mainly from neighboring states of Maranhão, Piauí, Bahia and Pará. Porto Nacional, Pedro Afonso and Natividade, founded on the former northern region of the state of Goiás, are the towns with the highest number of immigrants. In fact, they are relevant historical places formed by autochthonous people and immigrants. Since the above-mentioned towns present important variation aspects of the spoken Portuguese language in Tocantins, current study identifies and analyzes rhotic pronunciation, graphematically represented by $/ R /$ as a syllabic coda, in the three mentioned towns. Survey was undertaken with 24 topodynamic and topostatic informants distributed by gender and age. A segment of the questionnaire with 25 questions collected from the project "Topodynamic and Topostatic Linguistic Atlas of the State of Tocantins (ALiTTETO)" is investigated.

Keywords: Tocantins, Rhotic, Linguistic variation.

\section{RESUMEN}

La emancipación politica del estado de Tocantins, Brasil, se produjo hace 28 años. El estado se caracteriza por variedades lingüísticas debido al intenso flujo migratorio de personas provenientes principalmente de los estados vecinos de Maranhão, Piauí, Bahía y Pará. Porto Nacional, Pedro Afonso y Natividade, fundados en la antigua región norte del estado de Goiás, son las ciudades con mayor número de inmigrantes. De hecho, son lugares históricos relevantes formados por personas autóctonas e inmigrantes. Dado que los pueblos citados presentan 
importantes aspectos de la variación de la lengua portuguesa hablada en Tocantins, el presente estudio identifica y analiza la pronunciación del "rótico", representado grafemáticamente por / R /, en las tres ciudades mencionadas. Se realizó una encuesta con 24 informantes topodinámicos y toposáticos distribuidos por género y edad. Se investiga un segmento del cuestionario con 25 preguntas recogidas del proyecto "Atlas Topodámico y Topostático del Estado de Tocantins (ALiTTETO)".

Palabras clave: Tocantins; Rótico; Variación lingüística.

\section{INTRODUÇÃO ${ }^{1}$}

O Tocantins é o estado mais novo do Brasil, no que se refere sua emancipação política, datada em 1988. Abriga importante diversidade cultural e, consequentemente, linguística, resultado da colonização do respectivo território, além das intensas migrações ocorridas a partir da década de 1970.

A título de exemplo, as cidades de Natividade, Pedro Afonso e Porto Nacional, nos primórdios do território, contribuíram de forma significativa para o crescimento da região, sejam de forma econômica ou cultural. Além disso, essas localidades carregam em sua história a contribuição dos escravos e dos portugueses, no que diz respeito aos espaços, as ruas e prédios, construídos pelos primeiros habitantes, na época da exploração do ouro e outros minerais.

Considerando que os aspectos históricos, culturais e geográficos apresentam traços na língua, acreditamos que a análise de fatores linguísticos e extralinguísticos das citadas cidades podem contribuir para a descrição das dimensões variacionistas do português tocantinense. Optamos por trabalhar com o nível fonético-fonológico desse português, uma vez que essa categoria apresenta aspectos distintos em sua variação. Para esta finalidade, elencamos a variação do rótico, pois, assim como Lindau (1985), acreditamos que sua variação é existente em todas as línguas e "75\% das

\footnotetext{
${ }^{1} \mathrm{O}$ trabalho é decorrente de dois projetos PIBIC-CNPQ, desenvolvidos entre os anos de 2013 a 2016, vinculados à Universidade Federal do Tocantins, campus de Porto Nacional.
}

línguas do mundo possuem algum tipo de "r", sendo que $18 \%$ apresentam contrastes com dois ou mais desse segmento. [...]" (In OLIVEIRA, 2006, p.27).

Tendo em vista as presentes colocações, o trabalho possui a finalidade de identificar e analisar o rótico em posição de coda, tanto medial quanto externa, nas cidades de Pedro Afonso, Porto Nacional e Natividade, com cinco tipos de rótico comumente encontrados no português brasileiro:

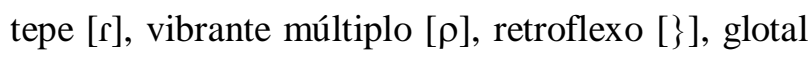
[h] e velar [x]; também verificamos o zero fonético ou apagamento da vibrante $[\theta]$.

$\mathrm{O}$ artigo encontra-se estruturado da seguinte forma: inicialmente esboçamos a metodologia utilizada no trabalho, ou seja, como se procedeu a pesquisa de campo e a análise dos dados coletados. Após, apresentamos um breve relato dos tipos de rótico encontrados em âmbito brasileiro para, posteriormente, apresentarmos nossas análises, distribuídas diatopicamente, ou seja, por localidade pesquisada.

\section{PASSOS METODOLÓGICOS DA PESQUISA}

O trabalho constituiu-se de dados coletados pelo Projeto "Atlas Linguístico Topodinâmico e Topoestático do Estado do Tocantins ALiTTETO”, coordenado pela Prof. ${ }^{a}$ Greize Alves da Silva em 12 localidades. Entretanto, para esse recorte utilizamos o corpus de três cidades: Porto Nacional, Pedro Afonso e Natividade. 
O respectivo Projeto coleta dados em duas vertentes: topoestática (pessoas nascidas na localidade, com os pais também da localidade) e topodinâmica (pessoas nascidas em outras localidades, mas que tenham migrado para a região de pesquisa há mais de 10 anos).

Os dados foram recolhidos junto a informantes de ambos os sexos, duas faixas etárias: de 18 a 30 anos de idade e de 50 a 65 anos, com escolaridade de, no máximo, o ensino médio. Em cada local de pesquisa inquirimos oito informantes estratificados, totalizando o número de 96.

Como nesse estudo analisamos o corpus de três cidades, totalizamos 24 informantes, distribuídos entre topodinâmicos e topoestáticos. Para fins didáticos, nesse recorte não trabalhamos com as variáveis sociais: idade, sexo e mobilidade, pois nosso intuito foi o de averiguar a arealidade das respostas, ou seja, a diatopia.

Para a análise dos dados foram utilizadas as respostas pertencentes ao subquestionário Fonético-Fonológico aplicado nas cidades de pesquisa. Assim, o corpus aferido constitui-se de 25 questões, das quais 14 verificam o rótico em coda medial e 11 em final de palavra ${ }^{2}$.

\section{RESULTADOS E DISCUSSÃO}

No Português Brasileiro, o rótico é caracterizado pela sua variedade; suas ocorrências incidem com maior propensão em posição interna (medial) e externa da palavra, ou seja, em disposição de coda (final de sílaba). Outros fatores, tanto sociais quanto linguísticos, contribuem para sua variabilidade.

\footnotetext{
2 São exemplos de itens em coda medial: cato[r]ze, ce[r]to, etc. Em coda externa: pergunta[r], mulhe[r], dentre outras.
}

Os fonemas ortograficamente marcados com a letra " $r$ " podem ser agrupados foneticamente, segundo Ladefoged e Maddieson (1996), em trills (vibrantes), taps, aproximantes e fricativos.

Os trills ou vibrantes são produzidos a partir da vibração da ponta da língua contra a região alveolar/dental; seu som ocorre por meio de vibrações de um dos órgãos articuladores - como a língua e os lábios - do sistema vocal humano contra o outro. Logo, passa-se uma corrente de ar na parte móvel e ela passa a vibrar durante a pronúncia de algum $\mathrm{som}^{3}$. Esse /r/ forte (ou vibrante múltipla) caracteriza a pronúncia de localidades sulistas, principalmente nos estados de Santa Catarina e Rio Grande do Sul (BRESCANCINI; MONARETTO, 2008).

Os taps (vibrante alveolar ou simples) são sons produzidos com um breve contato da língua em direção à região dental ou alveolar e que, posteriormente, retorna ao caminho inicial (LADEFOGED; MADDSION, 1996, p. 231).

Trabalhos sobre o tema demonstram que essa variante tem sido encontrada em localidades sulistas (BRESCANCINI; MONARETTO, 2008).

A aproximante ou retroflexa, também conhecida como R caipira [r], segundo Amaral (1920) é articulada quando

[...] a língua leva os bordos laterais mais ou menos até os pequenos molares de arcada superior e vira a extremidade para cima, sem tocá-la na abóbada palatal. E que não há quase nenhuma vibração tremulante (AMARAL, 1920, p.20).

Esse tipo de rótico é encontrado, em maior intensidade, nas regiões Sul, Sudeste e CentroOeste (BRANDÃO, 2007; CASTRO, 2006; SILVA, 2016).

\footnotetext{
${ }^{3}$ Nesse trabalho, para fins didáticos, não fizemos distinção entre vibrantes alveolares, uvulares, bilabiais, etc.
} 
Os sons fricativos são agrupados em velares e glotais. Os velares são produzidos pela aproximação e o contato entre o corpo da língua e o palato mole (véu palatino). Por seu turno, os glotais não menos fortes e duradouros que os velares. Tanto variantes velares quanto glotais ainda podem ser agrupadas quanto ao seu ponto de articulação: vozeadas (sonoras) ou desvozeadas (surdas). As sonoras têm seu som produzido quando se contrai o fluxo de ar por meio de um canal apertado no ponto de articulação, provocando uma turbulência, tornando-se assim sonora, pois as cordas vocais vibram durante a articulação (LADEFORGED; MADDIESON, 1996).

Estudiosos têm demonstrado que os sons fricativos vêm substituindo os trills e os taps em algumas regiões brasileiras, como é o caso da predominância da velar glotal nos estados do Norte e do Nordeste (CARDOSO, 2014, p. 103) [Carta F04 C3].
Há ainda registrado no português brasileiro a neutralização (zero fonético). $\mathrm{O}$ apagamento da variante acontece quando não há sua realização em final de palavras, e ocorre principalmente em verbos no infinitivo, exemplo: "torna[r]", "vende[r]", "vulga[r]", entre outros vocábulos. Segundo Callou et al.

\begin{abstract}
A hipótese é a de que a presença do $\boldsymbol{R}$, em coda final, constituiria, no caso uma marca morfológica de caráter redundante, já que para infinitivo e o subjuntivo futuro são marcados também pelo acento lexical na última sílaba (CALLOU et al. 2015, p.200)
\end{abstract}

É válido ressaltar que existem casos em que há o apagamento do rótico no meio da sílaba, sobretudo nos vocábulos em que a pronúncia do segmento é sempre [- vibrante] e [- anterior] (CALLOU et al. 2015, p.197).

Em suma, os róticos aqui apresentados podem ser sintetizados no seguinte quadro:

Quadro 1. Tipos de róticos e suas realizações

\begin{tabular}{|c|c|c|}
\hline Ś́MBOLOS & IDENTIFIÇĀo FONÉTICA & EXEMPLOS \\
\hline$[\mathrm{R}]$ & Vibrante múltipla & [Rlosa, a $[\mathbf{R}$ lor pe[R]dào, calor $\mathrm{R}]$ \\
\hline [1] & Tepe alveolar ou simples & 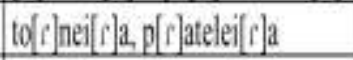 \\
\hline$[\mathrm{C}]$ & Retroflexo & to[l]neira, o[r]to, calo[c] \\
\hline$[x][y]$ & $\begin{array}{l}\text { Fricativa velar surda ou } \\
\text { sonora }\end{array}$ & $\begin{array}{l}{[\mathrm{x}] \text { oca, mo[x] ceeu[x]to, pe[x]dà, }} \\
\text { calo[x]. }\end{array}$ \\
\hline$[\mathrm{h}][\mathrm{h}]$ & $\begin{array}{l}\text { A fricativa glotal surda ou } \\
\text { sonora }\end{array}$ & 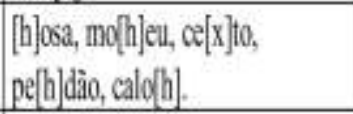 \\
\hline$[\theta]$ & $\begin{array}{l}0 \text { apagamento da variante ou } \\
\text { zero fonético }\end{array}$ & calö, pefume. \\
\hline
\end{tabular}

Fonte: Elaboração própria

Amostras do português falado em Pedro Afonso, Porto Nacional e Natividade

Os resultados analisados a partir das três localidades apontam que o rótico preterido nas cidades de pesquisa são os fricativos, sobretudo os glotais. Quanto às demais variantes, observemos que sua produtividade encontra-se atrelada à diatopia, ou seja, cada localidade de pesquisa demonstrou índices variados, além da posição do fonema (coda interna ou coda externa). Todos os resultados incluem as informações colhidas juntamente aos informantes 
topodinâmicos e topoestáticos. Os dados são evidenciados a seguir.

Pedro Afonso ${ }^{4}: \mathrm{Na}$ presente cidade coletamos o total de 107 respostas em coda interna e 81 na externa; os percentuais ficaram distribuídos conforme o quadro a seguir:

Quadro 2. Percentual - variantes coletadas em Pedro Afonso

\begin{tabular}{|l|c|c|}
\hline \multicolumn{1}{|c}{ Variante } & Coda interna & Coda externa \\
\hline Glotal & $\mathbf{7 9 . 4 \%}$ & $\mathbf{2 8 . 3 \%}$ \\
\hline Velar & $\mathbf{8 . 4 \%}$ & - \\
\hline Retroflexo & - & $\mathbf{1 . 2}$ \\
\hline Tepe & - & - \\
\hline Zero fonético & $\mathbf{1 2 . 1 \%}$ & $\mathbf{7 0 . 3 \%}$ \\
\hline
\end{tabular}

Fonte: Elaboração própria

Os resultados se diferenciam em relação a posição do fonema /R/, pois, em coda interna a norma constitui-se da fricativa glotal em quase $80 \%$ dos casos. Quando o fonema está no final da palavra, seja verbo ou substantivo, o apagamento da vibrante ocorre na maioria dos casos. Por seu turno, os apagamentos internos ocorrem principalmente em vocábulos como: borboleta, árvore e catorze; nesse último quase de forma categórica.

Há ainda a baixa incidência da velar na coda medial e do retroflexo na externa.

Porto Nacional ${ }^{5}$ : Nessa localidade tocantinense coletamos uma amostra de 108 dados

\footnotetext{
${ }^{4}$ Trata-se de uma das cidades mais antigas do Tocantins, com mais de 162 anos de emancipação política. Localizada entre os rios Sono e Tocantins, teve como principal fundador frei Rafael de Taggia, que no século XIX chegou à região para colonizar e catequizar os índios que ali viviam. Com o passar dos anos, Pedro Afonso tornou-se Arrial, depois Vila e, por fim, município. Com uma forte presença de imigrantes e turistas de outros estados, e de cidades circunvizinhas, possui população estimada em 11.539 habitantes, de acordo com o IBGE (2010)

5 Porto Nacional, em séculos passados, também foi ponto de exploração de ouro, fator que contribuiu para que houvesse a migração de mineradores, tropeiros, mascates e viajantes de todos os lugares, que passavam pelo local em busca de riquezas e bons negócios. Assim
}

em coda medial e 82 na externa, ilustrados percentualmente.

Quadro 3. Percentual - variantes coletadas em Porto Nacional

\begin{tabular}{|l|c|c|}
\hline \multicolumn{1}{|c|}{ Variante } & Coda interna & Coda externa \\
\hline Glotal & $\mathbf{7 5 . 9 \%}$ & $\mathbf{2 4 . 3 \%}$ \\
\hline Velar & $\mathbf{3 . 7 \%}$ & - \\
\hline Retroflexo & $\mathbf{6 . 4 \%}$ & - \\
\hline Tepe & $\mathbf{8 . 3 \%}$ & - \\
\hline Zero fonético & $\mathbf{5 . 6 \%}$ & $\mathbf{7 5 . 6 \%}$ \\
\hline
\end{tabular}

Fonte: Elaboração própria

Em Porto Nacional, na coda medial, embora a glotal também se constitua como variante predominante nos dados, há, por seu turno, a citação de outros tipos de rótico produtivos nos estados do Sudeste e Sul: o retroflexo e o tepe. Possivelmente, essa incidência seja reflexo dos processos migratórios mais intensos nessa localidade.

No que tange as codas finais, os percentuais tanto de glotais quanto de apagamentos são semelhantes à cidade analisada anteriormente. Apenas o índice de apagamentos internos em Porto Nacional é menor se comparado a Pedro Afonso.

Em Natividade ${ }^{6}$ os percentuais averiguados apresentam-se com algumas distinções: 113 registros para a coda medial e 84 para a externa:

como em Pedro Afonso e Natividade, Porto Nacional teve grande contribuição dos portugueses e dos escravos, no que se referem às casas, centros, ruas e igrejas históricas. A cidade foi fundada por efeito da Resolução Providencial $n^{\circ}$ 333, em 13 de julho de 1861, com a denominação de Porto Imperial. Anos depois, por Decreto da Lei Estadual $\mathrm{n}^{\circ}$ 21, em março de 1890, a cidade recebeu o nome definitivo de Porto Nacional. O município desenvolveu-se e hoje é considerada a Capital do Agronegócio e da Cultura do Tocantins. Em detrimento destes títulos, a cidade recebe um grande número de imigrantes de diversos lugares do Brasil e de outras localidades tocantinenses.

${ }^{6}$ Natividade foi fundada em 1734 como Arraial de Natividade e se tornou um dos lugares mais visitados do Tocantins, devido às construções históricas das igrejas, dos prédios e das residências antigas que, ao longo dos anos, não sofreram alterações em suas estruturas. No século XVIII, foi ponto de exploração do ouro (ação realizada pelos portugueses juntamente com os escravos), isso 
Quadro 4. Percentual - variantes coletadas em Natividade

\begin{tabular}{|l|c|c|}
\hline \multicolumn{1}{|c}{ Variante } & Coda interna & Coda externa \\
\hline Glotal & $\mathbf{6 9 . 9 \%}$ & $\mathbf{1 4 . 2 \%}$ \\
\hline Velar & $\mathbf{4 . 4 \%}$ & - \\
\hline Retroflexo & $\mathbf{1 3 . 2 \%}$ & - \\
\hline Tepe & $\mathbf{8 . 8 \%}$ & $\mathbf{1 . 1 \%}$ \\
\hline Zero fonético & $\mathbf{3 . 5 \%}$ & $\mathbf{8 4 . 5 \%}$ \\
\hline
\end{tabular}

Fonte: Elaboração própria

A glotal denota um percentual menor se comparado às outras duas localidades, não chegando a $70 \%$ do índice nativitano.

O retroflexo e o tepe apresentam-se mais produtivos também, alcançando o primeiro $13 \%$ das ocorrências; e o segundo quase 9\%, percentual semelhante ao apresentado em Porto Nacional.

Quanto a realização ou não do fonema em final de palavra, a glotal apresentou o mais baixo índice de todas as localidades. Houve ainda a pequena incidência da tepe em coda final.

A neutralização do fonema, por seu turno, apresentou o maior percentual registrado em contraponto com as demais localidades. O gráfico a seguir demonstra ilustrativamente os índices aqui apresentados:

Gráfico 1. Índices de ocorrência versus ausência do fonema /r/ em coda interna

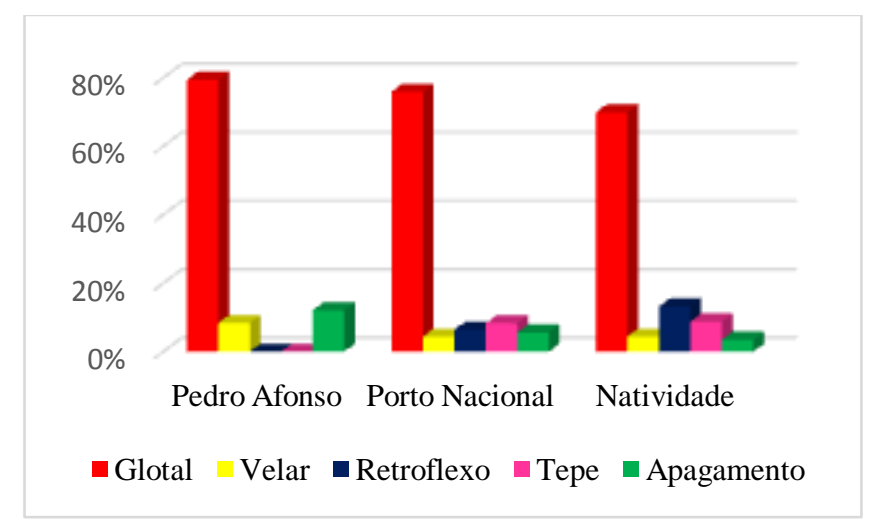

Fonte: Elaboração própria

contribuiu para o desenvolvimento do município e para a construção de vários monumentos
Gráfico 2. Índices de ocorrência versus ausência do fonema $/ \mathrm{r}$ / em coda externa

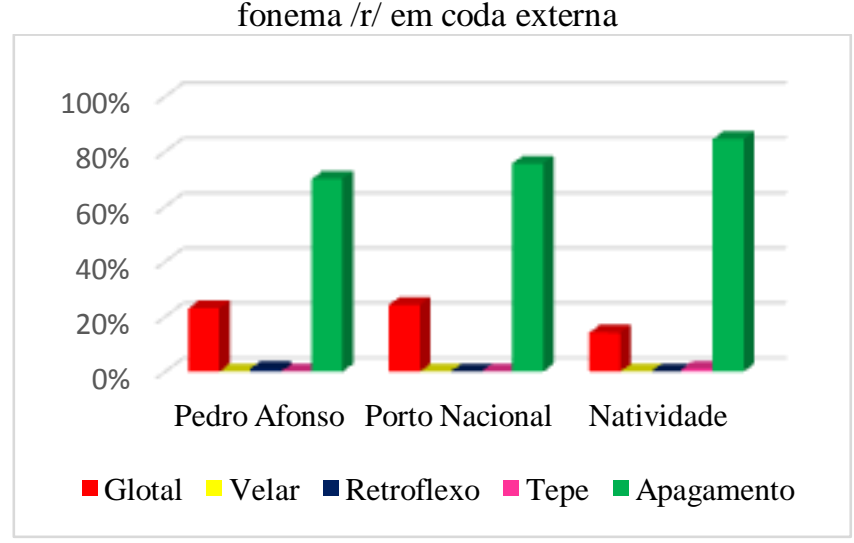

Fonte: Elaboração própria

Como podemos verificar, de acordo com a posição do fonema, a ocorrência do rótico é inversa. $\mathrm{Na}$ coda interna predominam as glotais (gráfico 1). Por conseguinte, no final de palavra preponderam os apagamentos do fonema (gráfico 2), sobretudo nos verbos, possivelmente dada a redundância morfológica apontada por Callou et al. (2015).

\section{CONCLUSÃO}

Das três localidades, podemos depreender algumas considerações. A norma fonética quanto à utilização do rótico, em grande maioria as glotais, denota que as cidades de pesquisa apontam semelhanças linguísticas com os estados nortistas e nordestinos, distanciando-se do Centro-Oeste, do Sul e do Sudeste (CARDOSO, 2014).

A presença de variantes tidas com tendência mais sulista, tais com o retroflexo e o tepe, pode estar atrelada a grupos procedentes de migração presentes nessas localidades, caso apontado em Pedro Afonso, por exemplo. Infelizmente, dada a pequena quantidade desse róticos não podemos aferir uma mudança linguística em curso. Além disso, é provável que o contexto antecedente e precedente de 
determinados vocábulos influi na presença das duas variantes citadas.

Da neutralização do fonema em coda medial e final, cuja tendência é apontada como procedente de um fenômeno morfológico, o maior índice ocorreu em Pedro Afonso e o menor em Natividade.

Ainda em Natividade, há o maior índice de retroflexos, o que poderia apontar traços oriundos de outros estados da federação, talvez do Centro-Oeste dada a alta ocorrência dessa variante em Goiânia, Cuiabá e Campo Grande (CARDOSO, 2014).

\section{AGRADECIMENTO}

Agradecemos à Universidade Federal do Tocantins - UFT, ao CNPq, ao Curso de Letras, campus de Porto Nacional e aos moradores das localidades escolhidas, por colaborarem com as entrevistas.

Todos os autores declararam não haver qualquer potencial conflito de interesses referente a este artigo.

\section{REFERÊNCIAS}

AGUILERA, V. A.; SILVA, H. C. Dois momentos do $/ \mathrm{r} /$ retroflexo em Lavras - MG: no Atlas Linguístico de Minas Gerais e nos dados do projeto do Atlas Linguístico do Brasil. Diadorim, v. 8, p. 125-142, 2011.

BRANDÃO, Sílvia Figueiredo. Nas trilhas do $-\mathrm{R}$ retroflexo. SIGNUM: estudos da linguagem. Londrina, v. 10, n. 2, p. 265-283, 2007.

BRESCANCINI, Cláudia, MONARETTO, Valéria Neto de Oliveira. Os róticos do Sul do Brasil: panorama e generalizações. SIGNUM: Estud. Ling., Londrina, n.11/2, p. 51-66, dez. 2008, p.51-52.

CALLOU, Dinah; SERRA, Carolina; CUNHA, CLAUDIA. Mudança em curso no português brasileiro: o apagamento do $\mathrm{R}$ no dialeto nordestino. Revista da ABRALIN, v.14, n.1, p. 195-219, jan./jun. 2015.

CARDOSO, SUZANA ALICE et al. Atlas Linguístico do Brasil. Vol.2. Londrina: UEL, 2014.
CASTRO, V. S. A resistência de traços do dialeto caipira: estudo com base em atlas linguísticos regionais brasileiros. 2006. 285f. Tese (Doutorado em Linguística) - Instituto de Estudos da Linguagem, Universidade Estadual de Campinas, Campinas, 2006.

LADEFOGED, P.; MADDIESON, I. The sounds of the world's languages. Cambridge: Blackwell, 1996.

LINDAU, M. The story of /r/. In: FROMKIN, V. A. Phonetic linguistics: essays in honor of Peter Ladefoged. Orlando: Academic Press, 1985. p. 157168 apud OLIVEIRA, C. C. Aquisição das consoantes róticas no português brasileiro e no espanhol: um reestudo comparativo. Tese (Doutorado em Letras - Linguística Aplicada) Pontifícia Universidade Católica do Rio Grande do Sul, Porto Alegre. 2006.

SILVA, Hélen Cristina. Pelas veredas do /R/ retroflexo. 2016 (Doutorado em Estudos da Linguagem). Universidade Estadual de Londrina, Londrina, 2016. 